Revue

Revue de l'histoire des religions

de Ihistoire des religions

Stéphane MOsès, Franz Rosenzweig. Sous l'Étoile, préface de Danielle COHEN-LEVINAS

Paris, Hermann («Le Bel Aujourd'hui »), 2009, 230 p., $21 \mathrm{~cm}, 25 €$, ISBN 978-2-7056-6849-5.

Dan Arbib

\title{
OpenEdition
}

Journals

Édition électronique

URL : http://journals.openedition.org/rhr/7958

DOI : $10.4000 /$ rhr.7958

ISSN : 2105-2573

Éditeur

Armand Colin

Édition imprimée

Date de publication : 1 septembre 2012

Pagination : 458-459

ISBN : 978-2200-92975-0

ISSN : 0035-1423

Référence électronique

Dan Arbib, «Stéphane mosès, Franz Rosenzweig. Sous l'Étoile, préface de Danielle cohen-LEVInAS 》, Revue de l'histoire des religions [En ligne], 3 | 2012, mis en ligne le 05 octobre 2012, consulté le 22 septembre 2020. URL : http://journals.openedition.org/rhr/7958 ; DOI : https://doi.org/10.4000/rhr.7958

Ce document a été généré automatiquement le 22 septembre 2020.

Tous droits réservés 


\section{Stéphane Mosès, Franz Rosenzweig. Sous l'Étoile, préface de Danielle COHEN-LEVINAS}

Paris, Hermann («Le Bel Aujourd'hui »), 2009, 230 p., $21 \mathrm{~cm}, 25 €$, ISBN 978-2-7056-6849-5.

Dan Arbib

\section{RÉFÉRENCE}

Stéphane MosÈs, Franz Rosenzweig. Sous l'Étoile, préface de Danielle COHEN-LEVINAS, Paris, Hermann (« Le Bel Aujourd'hui »), 2009, 230 p., 21 cm, 25 €, ISBN 978-2-7056-6849-5.

1 Parmi les récents et multiples hommages au regretté Stéphane Mosès (1931-2007), les dynamiques éditions Hermann publient un recueil de ses articles, parus en leur temps séparément et dans diverses revues de 1981 à 2001, ayant tous trait de près ou de loin à l'auteur de L'Étoile de la Rédemption, que Stéphane Mosès avait, comme on sait, beaucoup contribué à introduire en France à travers un ouvrage magistral (Système et Révélation: la philosophie de Franz Rosenzweig, Paris, Seuil, 1992; $2^{\mathrm{e}}$ éd. Bayard, 2003). Certaines études du présent volume sont du reste devenues assez classiques pour qu'il ne soit pas la peine ici de s'étendre sur leurs acquis, moins importants en un sens que le fait éditorial de leur reprise. On rappellera entre autres pour mémoire les formidables analyses sur « Le secret formel du récit biblique » (p. 115-129) ou sur « Émile Benveniste et la linguistique du dialogue » (p.181-205), et on saluera la publication en traduction française (due à Emmanuel Mosès) du texte sur « Rosenzweig et Hölderlin », prononcé par Mosès lors de sa remise du titre de Docteur Honoris Causa de l'Université de Tübingen (chap. VIII, p. 167-179).

2 Le lecteur s'étonnera peut-être que rien n'indique de prime abord qu'il s'agit là d'un recueil composé de façon posthume par des proches de Mosès; mais c'est que ce livre peut être considéré comme étant de part en part dû à Mosès, et à un double titre au 
moins. D'abord, parce que, comme nous l'apprend D. Cohen-Levinas, dans sa préface, "Stéphane Mosès avait prévu d'écrire un livre qui s'appellerait précisément Sous l'Étoile, reprenant ainsi les principaux idiomes de Rosenzweig, mais les confrontant aussi [...] à d'autres auteurs, tels que Goethe, Benjamin, Hölderlin ou Benveniste » (p. 8). Ce recueil ne prétend pas se substituer à l'ouvrage envisagé par Mosès et que la mort l'empêcha de réaliser, mais il en accomplit pour une part la tâche, orchestrant une pluralité de voix (Benjamin, Benveniste...) autour de la parole de Rosenzweig. Ensuite parce que chacun de ces textes, publiés ou prononcés du vivant de Mosès (aucun n'a fait l'objet d'une retouche par l'éditeur), est entièrement de Mosès luimême : on y sent la modestie du professeur, la patience du pédagogue, la passion du penseur. De sorte que le lecteur se retrouve bien « sous l'Étoile » : d'une part parce que toutes les analyses ici développées se rapportent à Rosenzweig comme à leur thème ou à leur point de fuite ; d'autre part, parce que, comme le suggère le titre de la préface de D. Cohen-Levinas, Mosès a tout $d$ ' « une étoile tombée du ciel », bonne étoile ou étoile du berger, destinée à guider le voyageur cheminant dans la philosophie juive allemande. Sous l'Étoile, donc, et non sur: parce que nous demeurons toujours en retard sur une telle pensée, et parce que nous pensons à partir d'elle, un peu comme Levinas et Mosès lui-même n'ont cessé de penser, non pas sur Rosenzweig, mais à partir de lui, sous lui, d'en émaner.

3 S'autorisera-t-on toutefois quelques critiques? Le bas de la p. 200 est inintelligible, inversant sans doute par erreur des lignes, des mots ou des phrases du texte d'origine (Revue de métaphysique et de morale, 2001/4, p. 522). Plus regrettable, la préface (au demeurant très belle et surtout d'un ton remarquablement juste) parle de publier « deux textes inédits en français [...] : un texte consacré à Rosenzweig et Hölderlin, un autre commentant la correspondance entre Franz Rosenzweig et Eugen Rosenstock » (p. 8). Or précisément, ce dernier article (chap.X, p. 208-230) pouvait déjà se lire, au mot près, dans L'ange de l'histoire, Paris, Seuil, 1992 / Gallimard, 2006, Première partie, chap. 1, II-V (p. 55-82). En revanche, une nouvelle édition de ce texte eût peut-être gagné à indiquer au lecteur qu'entre 1992 et 2009, Marc de Launay et Marc Crépon ont proposé une traduction de ladite correspondance (Franz Rosenzweig, Foi et savoir. Autour de L'étoile de la rédemption, Paris, Vrin, 2001, p. 47-128), dont la Présentation (p. 7) est dédiée... à Stéphane Mosès précisément! - Mais ce sont là des têtes d'épingles qui font d'autant mieux voir la valeur d'un tel ouvrage et le mérite de l'éditeur.

\section{AUTEURS}

\section{DAN ARBIB}

Fondation Thiers, CNRS. 